\title{
Future prisons and personalized trajectories
}

\author{
by CISCA JOLDERSMA \\ Custodial Institutions Agency, The Netherlands
}

\begin{abstract}
In the near future, imprisonment may no longer be the ultimate sanction. Imprisonment may be part of sanctions combined in an offender's trajectory. These trajectories will become more and more personalized and tailor-made. A trajectory consists of different options: pre-trial options; front-door options; options during stay in prison; pre-release options; and aftercare options. With regard to future prisons, five basic principles can be recognized: human dignity; the avoidance of further damage or harm; the right to develop the self; the right to be important to other people; and a stable and professional organization.
\end{abstract}

Keywords: Prisons of the Future; alternatives to detention; reentry

\section{Introduction}

How will prisons look and what kind of alternatives to imprisonment can be expected in the near future? These questions were investigated in the European project Prisons of the Future. The European Commission, as part of the Specific Program Criminal Justice, Action Grants 2013, funded the project. Specifically, the project relates to the program theme 'improving prison conditions' and the priority 'actions or studies that focus on alternatives to imprisonment'. The project started in 2014 and ended Spring 2016 with a final working conference and a final report (Joldersma, 2016).

During the project implementation, the emphasis on what alternatives to imprisonment are available was complemented by focusing on how to apply alternatives in practice. The project aimed at giving an impression of the future landscape of prison and probation practice. The landscape includes buildings such as future prisons, but also other institutional practices and the way they are shaped and organized. The central questions of the project were:

- What are current developments in prison and probation practice?

- What patterns can be recognized in prison and probation practice and how can they be assessed?

- What are challenges for the future?

The project was shaped in accordance with the methodology of participatory policy analysis (Geurts and Joldersma, 2001). Participants together reflected upon recent developments in prison policies and detected challenges for the future. The participatory methodology resembles methods of 'foresight' (Popper, 2008). More specifically, the project has certain characteristics in common with Future Search conferences, in which participants develop common ground by looking to the recent past to explore the future.

Participants in the project came from Sweden, Denmark, Finland, Belgium, and the Netherlands. The Confederation of European Probation Organizations participated in the project as well as the European Organization of Prison and Correctional Services. During the project, national teams were composed of the contributing countries, consisting of a policy maker, a prison governor, and a scientist. An expert team was also involved in the project. ${ }^{1}$ Together with all participants, three working sessions were held to arrive at preliminary answers to the above questions. The sessions focused on current developments in prisons and probation practices, patterns and principles, and challenges for the future. One of the sessions was partly shaped as a gaming/simulation in order to explore innovative options. 
At the start of the project, we assumed that it would be possible to detect a long list of alternatives to imprisonment. Furthermore, we implicitly expected one alternative at a time to be imposed on an offender. In this paper, the main project results with regard to these assumptions are shared and reflected upon. The results are mainly based on recent developments in the five northwestern European countries that were involved in the project, but they can also be of interest to other countries as well.

\section{Project findings}

\subsection{The wheel of sanctions}

The participating countries were asked to give insights into trends in the prison population in their countries in relation to probation population and criminality rates. Additionally, they were invited to draw an overview of current developments in prison and probation practice since the year 2000 and to reflect upon the alternatives that were at stake.

Different patterns were found with regard to a country's prison population in relation to the population of probation service. Whereas in Denmark the prison population remained stable over time, the number of prisoners decreased in Finland, Sweden, and The Netherlands. The Belgian prison population gradually increased. Overcrowding is still a problem to be solved by the Belgian government. In Denmark, it was observed that the prison population had become more complex and was more in need of support and treatment. A similar development was found in The Netherlands. One of the obvious reasons for a more complex prison population is that offenders of light offences are enabled more and more to stay out of prison due to alternative measures. However, in countries like Finland and The Netherlands, a large part of the prison population still consists of short-term prisoners.

In all countries involved, the favored alternatives to imprisonment are community service and electronic monitoring. For example, in Denmark, community services and electronic monitoring were the preferred alternatives. Community service - in combination with supervision - is often viewed as an appropriate alternative to a short-term prison sentence. In Finland, for example, until the year 2000, community services increased and short time prison sentences decreased at the same time. After the year 2000, however, the number of community services and short time prison sentences fluctuated. In Belgium, the focus has been, amongst others, on electronic monitoring. Electronic monitoring is also used in Belgium as an alternative to prison sentences for more serious offences, due to efficiency and prison overcrowding.

Other alternatives, such as contract treatment, differ per country and are dependent on the historical background. In Finland, the emphasis is on community services, since the country unsuccessfully tried to introduce contract treatment. In Sweden, contract treatment, community service, and electronic monitoring are the common sanctions. It is expected that the prison population in Sweden will decline further, due to electronic monitoring. A proposed measure in The Netherlands was intended to increase the use of electronic monitoring instead of imprisonment, but the measure was withdrawn due to lack of political support.

The range of preferred alternatives to imprisonment is quite small in the five different European countries together. The alternatives are summarized in the 'wheel of sanctions' (see Figure 1).

The wheel of sanctions shows that, in practice, only a few sanctions are commonly used. Conditional sentences can only be applied when the offender has agreed to comply with the conditions. Conditional sentences can involve different alternatives, such as fines, community services, and contract treatment. A breach of conditions usually implies that prison still functions as a last resort. A conditional sentence is usually accompanied by supervision by a probation officer in order to control whether the offender complies with the conditions. Probationary supervision can be viewed as a 'virtual imprisonment' concerning offenders' control in society. In practice, an increased use of alternatives to imprisonment does not always imply a similar decrease in the prison population. Therefore, net-widening effects can be designated, which means that as a whole, more people are under the influence of the criminal justice system (Joldersma, 2016, p. 138). ${ }^{2}$ 


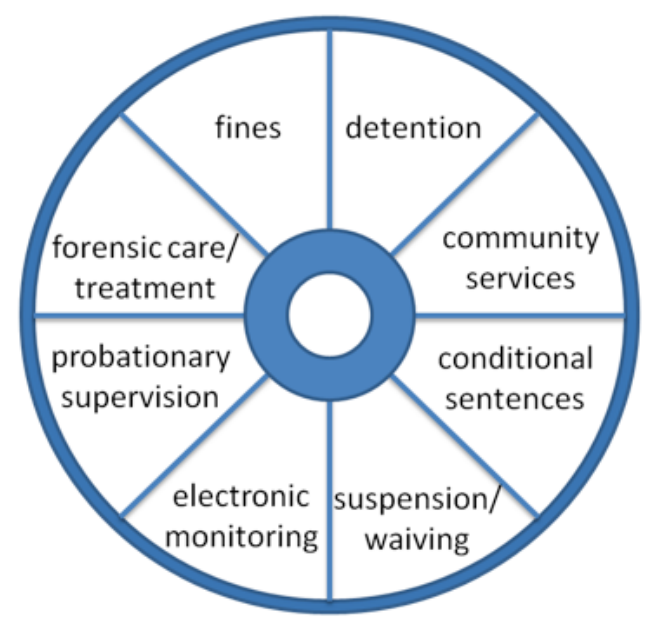

Figure 1. The wheel of sanctions (Joldersma, 2016, p. 150)

\subsection{Multiple applications of sanctions during the criminal justice process}

We already noted that sanctions in the wheel are not mutually exclusive; they complement each other. Moreover, we found that, besides as autonomous alternatives, sanctions are applied as an option within a prison sentence. For example, Maes (Joldersma, 2016, pp. 41-54) explains that electronic monitoring is not 'one single measure', but can be implemented in different stages of the criminal justice process, such as in the pre-trial phase, as well as in the sentencing phase.

A distinction can be made between options used in the pre-trial phase, so-called 'front-door' options; options during execution of the sentence and stay in prison (i.e., 'back-door' options or 'pre-release' options); and options that are applied after execution of the sentence (so-called 'after release' options or 'aftercare' options). For example, electronic monitoring is frequently used as a back-door option in many countries. In Finland, supervised probationary freedom has been introduced as a form of gradual release in which case the offender is supervised by prison staff outside the prison. In Sweden, special release measures are effected, in particular to juvenile prisoners and with the supervision of laymen. In The Netherlands, a revolving door measure is used for drug-addicted offenders, which includes a type of conditional release for residential or extramural care. Depending on national regulations, the applied options can be imposed by the judge, but also by the prison governor and/or a probation officer. With regard to a prison sentence, the use of different options in practice can be visualized as in Figure 2.

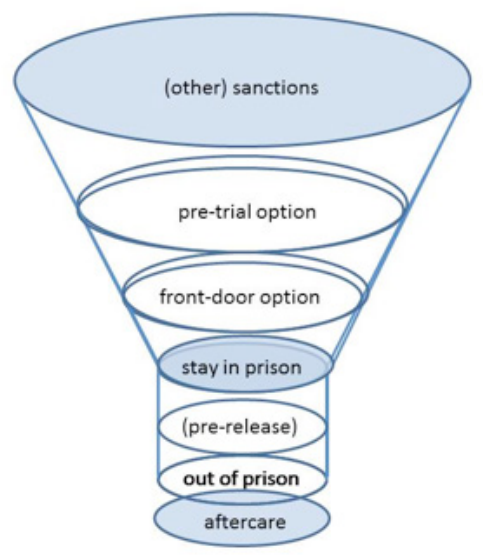

Figure 2. Funnel of options within a prison sentence (cf. Joldersma 2016, p. 140)

Figure 2 shows that different kinds of sanctions can be applied within a prison sentence. A pre-trial option concerns an alternative measure to remand custody. A front-door option is applied after the trial in order to avoid incarceration. A back-door option refers to possibilities for early release or pre-release from prison, 
due to appropriate behavior and/or reasons for reintegration. After release from prison, aftercare options or post-release options can be applied in order to facilitate reintegration and to improve cooperation with local municipalities and care providers. The options within a prison sentence generally contribute to shortening prison time (Joldersma, 2016, pp. 139-140). In time, the continuum of different measures, partly replacing or complementing a prison sentence, are broadened and enriched. Moreover, the boundaries between prison and community based-sanctions can blur. This trend can be seen in the Finnish basic principle of allocating prisoners to a setting with as open conditions as possible, including outside prisons.

\subsection{Personalized trajectories}

In the participating countries, it is quite common that prisoners have personal enforcement plans or 'detention and reintegration plans'. Each prisoner has his own personal plan with activities during the day and preparations for reentry in society. These plans are preferably developed with the involvement of the prisoners themselves. The plan is usually intended to be in accordance with the severity of the offence and the risks and needs of the offender. Already in the phase of conviction, risk-need analyses are sometimes used for individualized sentencing. More and more, treatment and rehabilitative interventions are tailored to the learning style and characteristics of the client. In the European countries involved, evidence-based practices are developing, based on the principles of Risk Needs Response or the 'what works' approach. The plans preferably take into account personal circumstances and hooks for change of the offender (Joldersma 2016, pp. 141-142).

Elaborating on the 'what works' approach, and in addition to the question 'what works' with regard to alternatives to imprisonment, we asked questions such as 'for whom, in what contexts and circumstances, and why?' These kinds of questions are commonly used in so-called realist evaluations in which working mechanisms are searched for (Pawson and Tilly, 2004). Referring to these additional questions, we found that sentences, their execution and follow-ups are tailored to the characteristics of the offender. Not only in the phase of conviction by court, but also in the phase of execution, sentences are tailored to characteristics of the offender, such as risks, needs, personal experiences, and hooks for change. Personalized sentencing can also be recognized in the personal enforcement or detention and reintegration plans. Consequently, in different phases of the criminal justice process, personalized sanctions and options are applied in a particular sequence to a particular offender (Joldersma, 2016, p. 151). The applied options together form a trajectory, taking into account circumstances of the offender as well as his social network. For example, the application of electronic monitoring needs family consent. Personalized trajectories in prison and probation practice can be compared, to some extent, to personalized medicine. Personalized medicine takes into account personal characteristics of the patient before prescribing medication (Joldersma, 2016, pp. 137-148).

\subsection{Theory-in-use in prison and probation practice}

Our experience during this project shows that it is hard to look at the future and imagine how future prisons will be shaped. According to the project participants, future prisons probably result from evolutionary and incremental changes of current practice, instead of revolutionary and disruptive changes. Therefore, we searched for current structural characteristics that influence current changes and probably will also be visible in the near future. We considered how to define the core characteristics of sanctions and options. For example, electronic monitoring can be defined in terms of electronic devices and the kind of technology used to control movements of the offender outside the home situation. However, shaping electronic monitoring for one situation can be different from shaping electronic monitoring for another situation. Therefore, we searched for the 'theory-in-use' of the applied sanctions and options. Theories-in-use are those theories that 'can be inferred from action; they are consistent with what people do'. They differ from 'espoused theories' or a theory a person or stakeholder 'claims to follow' (Argyris and Schön, 1974; Joldersma, 2016, pp. 54-64).

In the countries involved in the project, similar reasons or values are raised with regard to shaping prison and probation practice (see Figure 3).

The values can be compared to the espoused theory or the values participating countries claim to follow. The question is how these values are balanced in practice. Regardless of the particular option or sanction, common ground was found in similar basic principles with regard to prison and probation practice. The basic principles are: 
- Human dignity; the offender feels recognized as a person.

- The avoidance of further damage or harm: sanctions should not provide additional punishments.

- The right to develop the self: offenders have personal autonomy and are enabled to use their strengths.

- The right to be important to other people: persons are part of society and can contact their social network.

- A stable and professional organization: prison \& probation service is open-minded and focuses on professional development (Joldersma, 2016, pp. 14, 147).

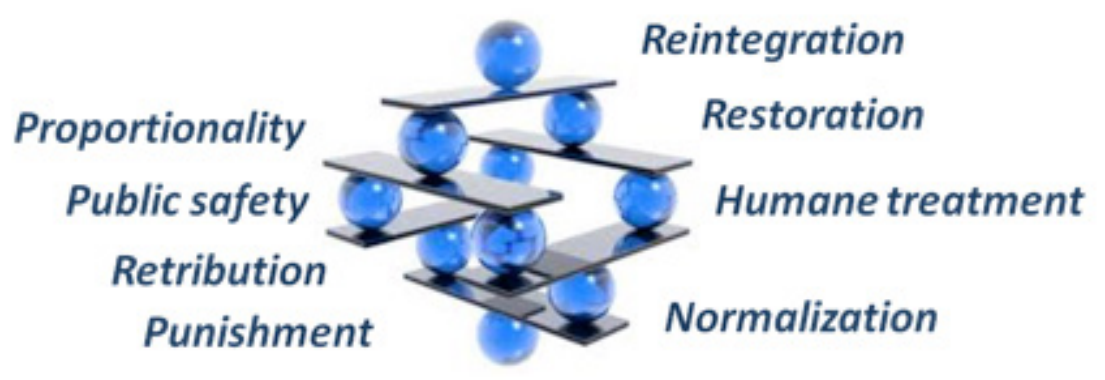

Figure 3. Balancing different values (Joldersma 2016, p. 152)

\section{Conclusions and future challenges}

In this article, the results of the European project Prisons of the Future were presented, along with the question of how to prepare for future of prison and probation practice and what to take into account.

The project was based on a participatory methodology, by elaborating on current changes in prison and probation practice in the participating countries and developing common ground in knowing where we are going.

Current features in prison and probation practice can be ordered along the 'wheel of sanctions', personalized trajectories and basic principles. The wheel of sanctions makes clear that there are only a few basic sanctions that are used autonomously or in combination with each other and function as options in a criminal justice process. The options are applied in a particular sequence, resulting in personalized trajectories that take personal characteristics of the offender into account. It is not the sanction or option as such which matters, but the way it is applied in practice, and for whom, and for what reason. Basic principles with regard to personalized trajectories in the context of public safety and reintegration relate to human dignity, avoidance of further damage, personal development, to be significant to others, and a professional organization.

Challenges for future prisons concern how the wheel of sanctions, personalized trajectories and basic principles are applied in practice. It raises new questions with regard to shortening prison time and connecting prisons and prisoners as much as possible to society. Is the future prison still functioning as a last resort for vulnerable offenders who are not able to comply with conditions? Other challenges concern the application of new communication technology and electronic monitoring, facilitating face-to-face relationships between staff and offenders, and maximizing opportunities for dynamic security. Finally, 'what works' approaches run the risk of becoming too instrumental with regard to applying instruments and techniques. How can we make sure that personalized trajectories contribute to the offender's real behavioral changes?

\section{References}

Argyris C. \& Schön, D.A. (1974.) Theory in practice: increasing professional effectiveness. San Francisco: Jossey Bass. Retrieved from www.actiondesign.com/assets/pdf/AScha3.pdf

Europris, ASA. (2016, March). Summary of the Final Working Conference of Prisons of the Future. Retrieved from www.Europris.com/projects

Future Search Conference. (2017) What is Future Search? Retrieved from http://www.futuresearch.net/meth- 
$\underline{\mathrm{od} / \text { whatis/ }}$

Geurts J.L.A. \& Joldersma C. (2001). Methodology for participatory policy analysis. European Journal of Operational Research 128, 300-310.

Joldersma, C. (Ed.). (2016). Final Report Prisons of the Future. DJI Hoofdkantoor: The Hague. Retrieved from www.Europris.com/projects

Pawson, R. \& Tilly, N. (2004). Realist Evaluation. Retrieved from http://www.communitymatters.com.au/ RE_chapter.pdf

Popper R. (2008). Foresight methodology: An overview and more...PREST--Manchester Institute of Innovation Research. Retrieved from http://www.forschungsinfo.de/archiv/iFQ Jahrestagung_08/beitraege/ popper.pdf

\section{Endnotes}

${ }^{1}$ The expert team consisted of Alison Liebling (UK), expert on moral quality of prison life; Eric Maes (Belgium), expert on electronic monitoring; and Bas Vogelvang (The Netherlands), expert on probation and circles of accountability and support.

${ }^{2}$ Contribution of the Confederation of European Probation Organizations CEP to working sessions of Prisons of the Future, based on a small survey amongst its members.

Cisca Joldersma was senior strategic adviser at the Custodial Institutions Agency and project manager of Prison of the Future. Previously, she was an associate professor of policy \& organization science at Tilburg University and a member of the Dutch Parliament. Currently, she works as a Research Coordinator for care at CAOP The Netherlands. 